\title{
The endogenous peptide antisecretory factor promotes tonic GABAergic signaling in CA1 stratum radiatum interneurons
}

\author{
Joakim Strandberg ${ }^{1}{ }^{*}$, Catarina Lindquist $^{1}$, Stefan Lange ${ }^{2}$, Fredrik Asztely ${ }^{1}$ and Eric Hanse ${ }^{1}$ \\ 1 Institute of Neuroscience and Physiology, Sahlgrenska Academy, University of Gothenburg, Göteborg, Sweden \\ 2 Institute of Biomedicine, Sahlgrenska Academy, University of Gothenburg, Göteborg, Sweden
}

\section{Edited by:}

Enrico Cherubini, International School

for Advanced Studies, Italy

Reviewed by:

Annalisa Scimemi, State University of

New York at Albany, USA

Kimmo Jensen, Aarhus University

Hospital, Denmark

*Correspondence:

Joakim Strandberg, Institute of Neuroscience and Physiology,

Sahlgrenska Academy, University of Gothenburg, Box 432, SE 40530

Göteborg, Sweden

e-mail:

joakim.strandberg@physiol.gu.se
Tonic GABAergic inhibition regulates neuronal excitability and has been implicated to be involved in both neurological and psychiatric diseases. We have previously shown that the endogenous peptide antisecretory factor (AF) decreases phasic GABAergic inhibition onto pyramidal CA1 neurons. In the present study, using whole-cell patch-clamp recordings, we investigated the mechanisms behind this disinhibition of CA1 pyramidal neurons by AF. We found that application of $A F$ to acute rat hippocampal slices resulted in a reduction of the frequency, but not of the amplitude, of spontaneous inhibitory postsynaptic currents (sIPSCs) in CA1 pyramidal neurons. Miniature inhibitory postsynaptic currents (mIPSCs), recorded in the presence of tetrodotoxin (TTX), were however not affected by AF, neither in CA1 pyramidal cells, nor in stratum radiatum interneurons. Instead, AF caused an increase of the tonic $\mathrm{GABA}_{A}$ current in stratum radiatum interneurons, leaving the tonic GABAergic transmission in CA1 pyramidal cells unaffected. These results show that the endogenous peptide AF enhances tonic, but not phasic, GABAergic signaling in CA1 stratum radiatum interneurons, without affecting tonic GABAergic signaling in CA1 pyramidal neurons. We suggest that this increased tonic GABAergic signaling in GABAergic interneurons could be a mechanism for the AF-mediated disinhibition of pyramidal neurons.

Keywords: tonic inhibition, GABA, IPSC, hippocampus, CA1

\section{INTRODUCTION}

Antisecretory factor $(\mathrm{AF})$ is an endogenous $43 \mathrm{kDa}$ protein that is expressed in all mammalian tissues and plasma investigated so far (Johansson et al., 1995, 2009; Lange et al., 1999; Lange and Lönnroth, 2001; Ulgheri et al., 2010). The protein was named AF due to its capacity to counteract enterotoxin-induced intestinal hypersecretion, but later studies have shown that $\mathrm{AF}$ is also a potent anti-inflammatory agent (Johansson et al., 1997a, 2013; Eriksson et al., 2003; Davidson and Hickey, 2004a,b; Graber et al., 2011; Mane et al., 2011). Protein AF, which is also named S5a or RPn10, is a component of the $26 \mathrm{~S}$ proteasome (Ulgheri et al., 2010). It can either be associated to the proteasome, or appear in a free form. This free form appears to have functions not associated with the proteasome.

The "active site" of AF, i.e., the part of the AF protein which effectuates the anti-secretory and anti-inflammatory action, can be isolated to an eight amino acid long sequence at the $\mathrm{N}$-terminal part of the protein, IVCHSKTR (Johansson et al., 1997b). A somewhat larger peptide, AF-16, also including the active sequence, is more stable and therefore acceptable for experimental work (Jennische et al., 2008). AF has been demonstrated to counteract various forms of intestinal hypersecretion in clinical studies, and a number of experimental studies have demonstrated a protective, regulating effect of AF-16 in various models of tissue injury.
Thus, AF-16 normalized the intracranial pressure and abolished mortality in rats with experimental herpes simplex 1 encephalitis (Jennische et al., 2008), while a high endogenous level of plasma $\mathrm{AF}$ prevented a rise in intracranial pressure and improved the cognitive functions in rats exposed to focal brain injury (Säljö et al., 2010). In a mouse colitis model treatment with AF decreased the extent of inflammation even in a late phase of the disease (Mane et al., 2011). Furthermore, the endogenous level of AF varies between mice strains. Thus, strains with a high AF mRNA expression are more resistant to autoimmune encephalitis than strains with a lower AF mRNA expression (Davidson and Hickey, 2004a). Taken together, the results of these studies suggest that the major effect of $\mathrm{AF}$ is to regulate/modulate hypersecretion and inflammatory reactions. The cellular mechanisms that mediate these anti-inflammatory and anti-secretory effects by AF are, however, largely unknown.

We have previously shown in vitro that AF-16 affects neuronal signaling in the brain (Kim et al., 2005). Specifically, application of AF-16 to acute rat hippocampal slices reduces GABAergic transmission onto CA1 pyramidal cells without affecting glutamatergic transmission. This disinhibitory effect was mimicked by feeding the rats with a diet containing hydrothermally processed cereals and by per oral administration of cholera toxin. In the present study we have investigated mechanisms behind this 
suppression of GABAergic transmission. We found that AF-16 enhances the tonic GABAergic current in CA1 stratum radiatum interneurons, without affecting the tonic GABAergic current in CA1 pyramidal neurons. We propose that the increased tonic GABAergic signaling in the GABAergic interneurons contributes to the AF-induced reduction of the feed-forward inhibition in this hippocampal region.

\section{MATERIALS AND METHODS HIPPOCAMPAL SLICE PREPARATION}

Hippocampal transverse slices (300-400 $\mu \mathrm{m}$ thick) were prepared from male P38-P60 Wistar rats, however in the experiments illustrated in Figure 6 both Wistar and Sprauge-Dawley rats were used. There was no difference in the effect of AF-16 between the two strains (see Section Results). Rats were anesthetized with isoflurane prior to decapitation using a guillotine. After decapitation the skull was opened and the brain hemispheres were put in a $4^{\circ} \mathrm{C}$ solution containing (in $\mathrm{mM}$ ): 110 cholineCl, $2.5 \mathrm{KCl}$, $1.25 \mathrm{NaH}_{2} \mathrm{PO}_{4}, 25 \mathrm{NaHCO}_{3}, 0.5 \mathrm{CaCl}_{2}, 7 \mathrm{MgCl}_{2}, 1.3$ ascorbic acid and 7 D-glucose. Hippocampal slices were prepared using a vibratome (Microtome HM 650 V, Thermo Fisher Scientific, Loughborough, UK) in the same solution as above and then transferred to a storage chamber with a $25^{\circ} \mathrm{C}$ artificial cerebrospinal fluid (ACSF) containing (in $\mathrm{mM}$ ): $1.25 \mathrm{NaH}_{2} \mathrm{PO}_{4}, 124 \mathrm{NaCl}$, $26 \mathrm{NaHCO}_{3}, 3 \mathrm{KCl}, 4 \mathrm{MgCl}_{2}, 2 \mathrm{CaCl}_{2}, 5$ ascorbic acid, 4 D,Llactic acid, 3 myo-inositol and $10 \mathrm{D}$-glucose. For experiments where slices were incubated in AF-16 the storage solution also contained $0.5 \mu \mathrm{g} / \mathrm{ml}$ AF-16 (this concentration of AF-16 was used in all experiments of this study). The slices were kept in the storage solution for $1-6 \mathrm{~h}$ before being transferred to the recording chamber. In the recording chamber the slices were perfused (2-3 $\mathrm{ml} / \mathrm{min}$ ) with ACSF containing (in $\mathrm{mM}$ ): $1.25 \mathrm{NaH}_{2} \mathrm{PO}_{4}$, $124 \mathrm{NaCl}, 26 \mathrm{NaHCO}_{3}, 3 \mathrm{KCl}, 2 \mathrm{MgCl}_{2}, 2 \mathrm{CaCl}_{2}$ and $10 \mathrm{D}$ glucose. The perfusion ACSF also contained AF-16 in experiments where slices had been incubated in AF-16. All solutions were continuously bubbled with gas containing 95\% $\mathrm{O}_{2}$ and $5 \% \mathrm{CO}_{2}$ (pH 7.4) (AGA Gas AB, Lidingö, Sweden).

\section{RECORDING AND ANALYSIS}

CA1 pyramidal cells and stratum radiatum interneurons were visually identified using infrared differential interference contrast video microscopy mounted on an Olympus BX51WI microscope. Whole-cell patch-clamp recordings were performed with a patch clamp amplifier (EPC-9, Heka Elektronik, Lambrecht, Germany) at a sampling frequency of $10 \mathrm{kHz}$ and filtered at $2.9 \mathrm{kHz}$. To record $\mathrm{GABA}_{\mathrm{A}}$ receptor-mediated responses the neurons were voltage clamped at $0 \mathrm{mV}$ and the pipette solution contained (in $\mathrm{mM}$ ): $130 \mathrm{Cs}$-methanesulfonate, $2 \mathrm{NaCl}, 10 \mathrm{HEPES}$, 0.6 EGTA, 5 Qx-314, 4 Mg-ATP and 0.4 GTP (pH 7.3, adjusted with D-gluconic acid). Patch pipettes (borosilicate, OD $1.5 \mathrm{~mm}$, ID $0.86 \mathrm{~mm}$ ) were pulled with a horizontal Flaming/Brown micropipette puller (P-97, Sutter Instrument Company, Novato, CA, USA) and they had a resistance of 2.8-6.6 M $\Omega$. Series resistance was monitored using a 5 or $10 \mathrm{mV}$ hyperpolarizing pulse and was not allowed to change more than $20 \%$. All recordings were performed at room temperature. Analysis of miniature inhibitory postsynpatic currents (mIPSCs) and spontaneous
IPSCs (sIPSCs) was performed using the Mini Analysis Program (version 5.6.28, Synaptosoft Inc, Fort Lee, NJ, USA). The first 100 miniature/spontaneous events at every given time point were analyzed. The cumulative plots shown in the figures were made from averaging the individual cumulative plots based on the normalized values from the time points indicated. Input resistance and holding current were measured using custom made software in Igor Pro (WaveMetrics Inc, Lake Oswego, OR, USA). The input resistance was measured using a hyperpolarizing pulse of 5 or $10 \mathrm{mV}$ for $200-500 \mathrm{~ms}$. Picrotoxin (PTX) $(100 \mu \mathrm{M})$ was used to block $\mathrm{GABA}_{\mathrm{A}}$ receptor mediated currents. The voltage-gated sodium channel blocker tetrodotoxin (TTX) $(1 \mu \mathrm{M})$ was used to block action potentials when recording mIPSCs.

\section{STATISTICS}

All data are expressed as means \pm standard error of the mean. Statistical significance was evaluated using Student's $t$-test for paired or independent data and Kolmogorov-Smirnov test for distributions.

\section{DRUGS AND CHEMICALS}

Chemicals were from Sigma-Aldrich (Steinheim, Germany) and Merck (Damstadt, Germany) except for TTX (Abcam Biochemicals, Cambridge, UK and Alomone labs, Jerusalem, Israel). The AF-16 peptide (VCHSK TRSNP ENNVG L) and the scrambled AF-16 peptide (GRSNK VENCL PHNST V) were synthesized with solid phase synthesis (Ross-Petersen AS, Copenhagen, Denmark).

\section{RESULTS}

\section{ANTISECRETORY FACTOR (AF-16) REDUCES THE FREOUENCY OF SPONTANEOUS INHIBITORY POSTSYNAPTIC CURRENTS (IPSCS) ONTO CA1 PYRAMIDAL NEURONS}

We have previously shown, using extracellular field recordings, that AF-16 reduced evoked feed-forward GABAergic inhibition onto CA1 pyramidal neurons (Kim et al., 2005). In the present study, using whole-cell patch clamp recordings, we further examined the effect of AF-16 on GABAergic inhibition onto CA1 pyramidal neurons. We first investigated spontaneous action potential-dependent sIPSCs in CA1 pyramidal neurons. 50-60 min after applying AF-16 to the hippocampal slice there was a decrease in the frequency of sIPSCs to $78 \pm 7 \%(p<0.05$, paired $t$-test) of the frequency obtained prior to the application, without a significant change in the averaged amplitude $95 \pm 7 \%(p=0.52$, paired $t$-test) of the sIPSCs $(n=8)$ (Figure 1A). As described previously (Kim et al., 2005), the effect of AF-16 on GABAergic transmission developed slowly over more than $30 \mathrm{~min}$. There was no run-down of phasic GABAergic signaling (in the presence of TTX) in control experiments (Figures 2C, D). In parallel with the average change in sIPSC frequency, the averaged cumulative distribution of sIPSC inter-event intervals before and $60 \mathrm{~min}$ after AF-application was significantly altered (Figure 1B) $(p<0.05$, Kolmogorov-Smirnov test). The averaged cumulative distribution of sIPSC amplitudes was not significantly altered (Figure 1C) ( $p=$ 0.92 , Kolmogorov-Smirnov test). This result confirms previous results (Kim et al., 2005) showing a disinhibitory effect of AF. 
A
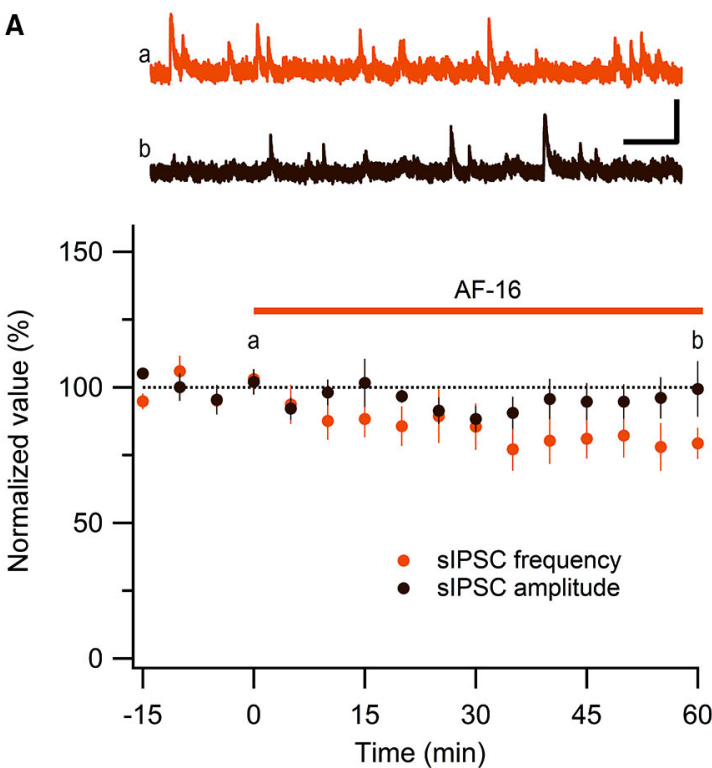

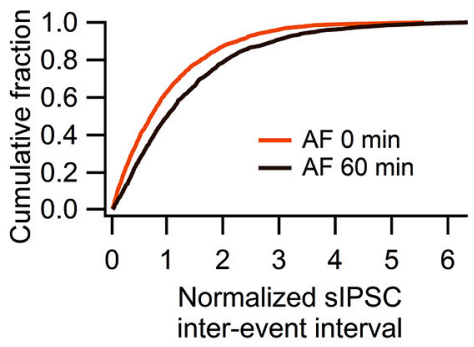

C

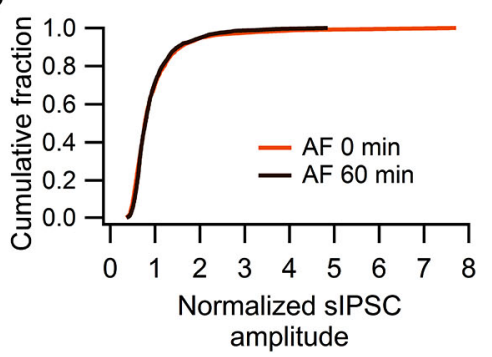

FIGURE 1 | AF-16 reduces the frequency of sIPSCs in CA1 pyramidal neurons. (A) Summary graph of average ( \pm s.e.m.) frequencies and amplitudes of recorded sIPSCs in CA1 pyramidal neurons $(n=8)$ during application of AF-16. Representative traces from time points a (orange trace before the application of AF) and $b$ (dark brown trace 60 min after the application of AF) are shown at the top, scale bar represents $40 \mathrm{pA}$ and $1 \mathrm{~s}$. (B) Effect of AF-16 on the cumulative distribution of sIPSC inter-event intervals $(n=8)$. (C) Effect of AF-16 on the cumulative distribution of SIPSC amplitudes $(n=8)$.

\section{ANTISECRETORY FACTOR (AF-16) DOES NOT ALTER MINIATURE INHIBITORY POSTSYNAPTIC CURRENT (mIPSC) AMPLITUDE OR FREQUENCY ONTO CA1 PYRAMIDAL CELLS}

To further investigate the reduced GABAergic inhibition onto CA1 pyramidal cells we examined the effect of AF-16 on spontaneous action potential-independent mIPSCs in CA1 pyramidal neurons. In the presence of $1 \mu \mathrm{M}$ TTX, blocking all action potentials, we measured mIPSC frequency and amplitude before and $60 \mathrm{~min}$ after application of AF-16 (Figure 2). Application of AF-16 to the hippocampal slice had no significant effect on mIPSC frequency or amplitude (Figures 2A, B). The averaged frequency and amplitude of mIPCSs $60 \mathrm{~min}$ following application of AF-16 were $101 \pm 4 \%$ and $101 \pm 4 \%$, respectively $(n=$ $6)$, compared to before application of AF-16. To control for unspecific changes during whole-cell recordings we also measured mIPSC frequency and amplitude in control experiments without drug application (Figures 2B-D). The average frequency and amplitude of the mIPSCs were not significantly changed over $60 \mathrm{~min}$ in these experiments $(99 \pm 5 \%$ and $96 \pm 4 \%$, respectively, $n=7)$. The averaged cumulative distributions of inter-event intervals and amplitudes of mIPSCs before and $60 \mathrm{~min}$ after AF-application and corresponding controls were not significantly altered (Figures 2E, F) (AF: $p=0.99$ for inter-event intervals and $p=0.98$ for amplitudes, controls: $p=0.85$ for inter-event intervals and $p=0.78$ for amplitudes, Kolmogorov-Smirnov test). Taken together, AF-16 reduces the frequency of sIPSCs in CA1 pyramidal neurons without changing the frequency or amplitude of mIPSCs.

\section{ANTISECRETORY FACTOR (AF-16) ENHANCES THE TONIC, BUT NOT PHASIC, GABA A RECEPTOR-MEDIATED CURRENT IN CA1 STRATUM RADIATUM INTERNEURONS}

Most of the GABAergic inhibitory synaptic contacts onto CA1 pyramidal neurons are from local interneurons in the CA1 stratum radiatum (Klausberger, 2009; Bezaire and Soltesz, 2013). Since AF-16 decreased the frequency of action potential dependent sIPSCs, but not mIPSCs, onto CA1 pyramidal cells we speculated that the effect of AF-16 on GABAergic transmission could be due to a lowering of the intrinsic excitability of the interneurons making them less likely to signal onto the pyramidal cells. Increasing the tonic GABAergic current in the interneurons is one possible mechanism that could result in such a lowering of their intrinsic excitability. We therefore measured the tonic $\mathrm{GABA}_{\mathrm{A}}$ receptor-mediated current in stratum radiatum interneurons by recording the change in holding current and input resistance after application of the $\mathrm{GABA}_{\mathrm{A}}$ receptor channel blocker PTX in control slices and in slices that had been incubated in AF-16 for $>1 \mathrm{~h}$ before measuring. Slices incubated in AF-16 had a larger tonic $\mathrm{GABA}_{\mathrm{A}}$ receptor-mediated transmission both measured as the change in holding current (AF-16: $9.6 \pm 1.4 \mathrm{pA}, n=8$, compared to control: $0.9 \pm 0.8 \mathrm{pA}, n=5, p<0.001$, unpaired $t$-test; Figure 3A) and measured as the change in input resistance (AF-16: $16 \pm 4 \%, n=8$, compared to control: $-4 \pm 8 \%, n=5, p<$ 0.05 , unpaired $t$-test) (Figure $3 \mathrm{~B}$ ) after PTX application. A tonic $\mathrm{GABA}_{\mathrm{A}}$ receptor-mediated transmission could be measured in all of the interneurons incubated in AF-16 (Figures 3A, B). As the effect of AF-16 on GABAergic transmission onto CA1 pyramidal 
A

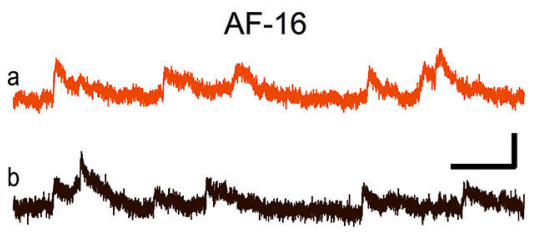

C

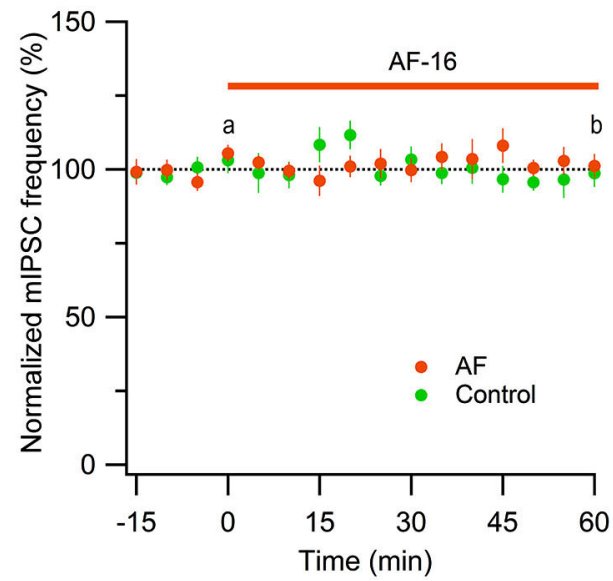

E

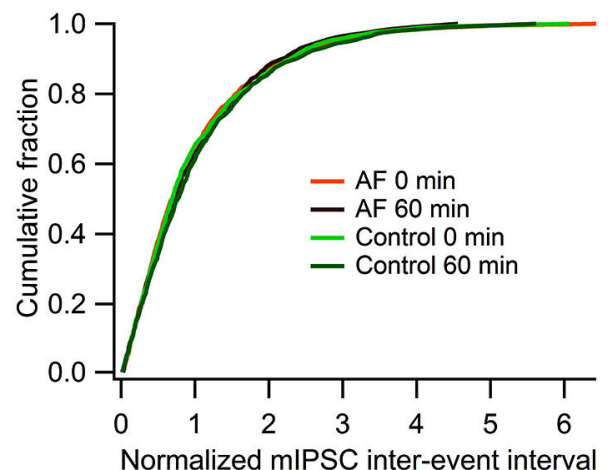

FIGURE 2 | No effect of AF-16 on mIPSCs in CA1 pyramidal neurons. (A) Representative traces from time points a (orange trace before the application of AF) and $b$ (dark brown trace 60 min after the application of AF) in (C) and (D) from an experiment with application of AF-16, scale bar represents $20 \mathrm{pA}$ and $100 \mathrm{~ms}$. (B) Representative traces from time points a (green trace at time " 0 min") and b (dark green at time "60 min") in (C) and (D) from a control experiment without application of AF-16, scale bar represents $20 \mathrm{pA}$ and $100 \mathrm{~ms}$. (C) Summary graph of average ( \pm s.e.m.)
B

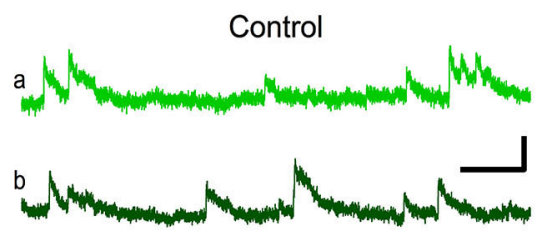

D

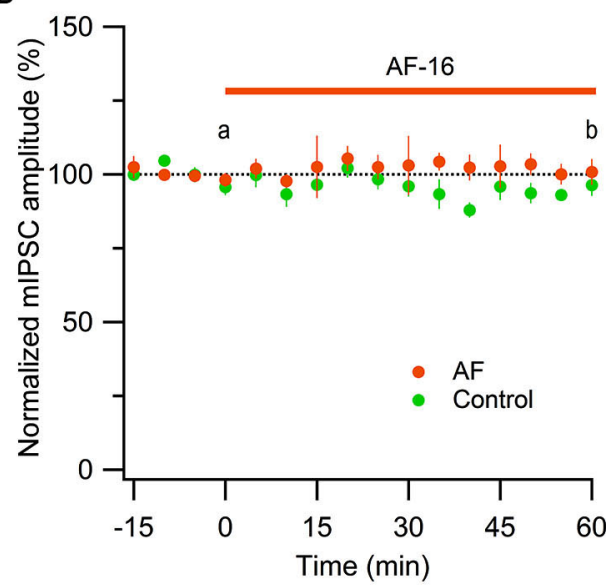

$\mathbf{F}$

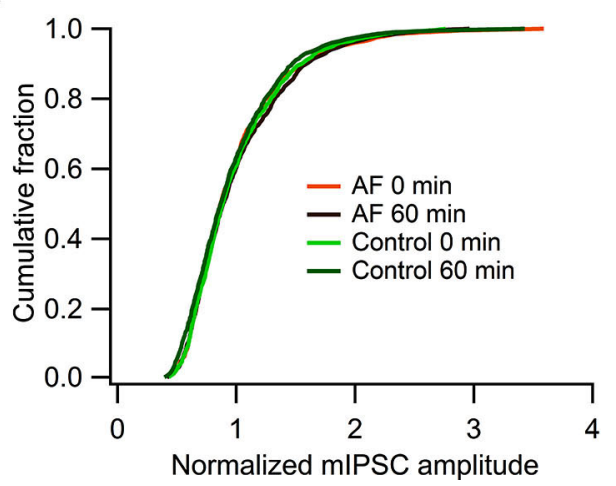

frequencies of recorded mIPSCs in CA1 pyramidal neurons exposed to AF-16 $(n=6)$ and controls not exposed to AF-16 $(n=7)$. (D) Summary graph of average ( \pm s.e.m.) amplitudes of recorded mIPSCs in CA1 pyramidal neurons exposed to AF-16 $(n=6)$ and controls $(n=7)$.

(E) Cumulative distributions of mIPSC inter-event intervals at 0 min and 60 min after AF-16 application $(n=6)$ and control $(n=7)$. (F) Cumulative distributions of mIPSC amplitudes at $0 \mathrm{~min}$ and $60 \mathrm{~min}$ after AF-16 application $(n=6)$ and control $(n=7)$. cells develops slowly over more than $30 \mathrm{~min}$, we also wanted to measure how the effect of AF-16 on tonic GABAergic transmission in CA1 stratum radiatum interneurons develops over time. We measured the effect of AF-16 as the change in input resistance over 60 min after application of AF-16 to the ACSF. 60 min after the application of AF-16 the input resistance had decreased by $-22 \pm 6 \%(n=8)$ (Figure 4A), significantly different from the observed effect on the input resistance by a scrambled AF-16 peptide $(6 \pm 7 \%, n=8, p<0.05$, unpaired $t$-test) (Figure 4B).

These results show that $\mathrm{AF}$ causes an increased tonic GABAergic signaling onto GABAergic interneurons. We next wanted to examine whether phasic GABAergic inhibition onto these interneurons was affected by AF. We therefore recorded mIPSCs in stratum radiatum interneurons before and after the application of AF-16. As can be seen in Figure 5A there was no significant change in the frequency $(105 \pm 5 \%)$ or the amplitude $(101 \pm 5 \%)$ of mIPSCs 50-60 min following application of AF-16 $(n=6)$. The averaged cumulative distributions of inter-event intervals and amplitudes of mIPSCs before and $60 \mathrm{~min}$ after AF-application were not significantly altered (Figures 5B, C) $(p=0.99$ and $p=0.99$, respectively, Kolmogorov-Smirnov test). These results thus indicate that AF 


\section{A}
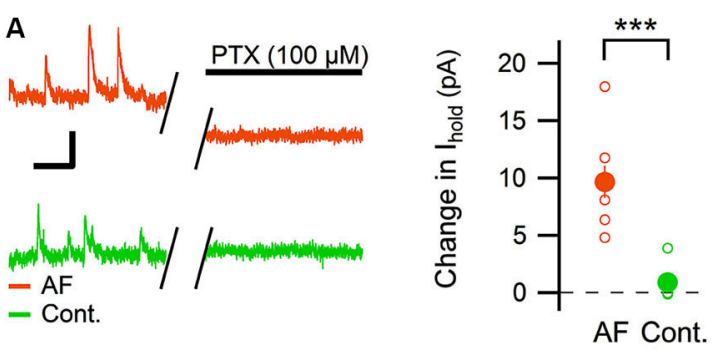

B
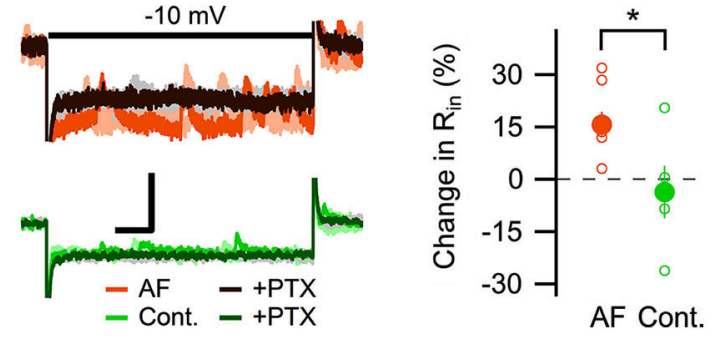

FIGURE 3 | AF-16 enhances tonic GABAergic transmission in CA1 stratum radiatum interneurons. (A) Diagram showing the effect of PTX on the holding current in CA1 stratum radiatum interneurons incubated in AF-16 ( $n=8)$ and control $(n=5)$. Open circles represent the individual experiments while the filled circles represent the average ( \pm s.e.m.) values. On the left are representative traces before and after application of PTX, scale bar represents $10 \mathrm{pA}$ and $250 \mathrm{~ms}$. (B) Diagram showing the effect of PTX on the input resistance in CA1 stratum radiatum interneurons incubated in AF-16 $(n=8)$ and control $(n=5)$. Open circles represent the individual experiments while the filled circles represent the average ( \pm s.e.m.) values. On the left are representative traces during a $-10 \mathrm{mV}$ test pulse before (orange/light orange and green/light green colors for AF and control, respectively) and after (dark brown/gray and dark green/gray colors for AF and control, respectively) application of PTX, scale bar represents $30 \mathrm{pA}$ and $75 \mathrm{~ms} .{ }^{*} p<0.05,{ }^{* * *} p<0.001$.

enhances tonic, but not phasic, GABAergic inhibition onto these interneurons.

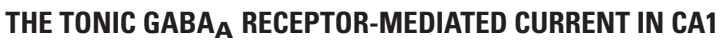 PYRAMIDAL CELLS IS NOT ALTERED BY ANTISECRETORY FACTOR (AF-16)}

The change in tonic GABAergic transmission onto interneurons could depend on a change in the expression levels or kinetics of the GABA receptors, but it could also depend on an increased level of ambient GABA (Jensen et al., 2003; Glykys and Mody, 2007; Song et al., 2013). An increased level of ambient GABA is expected to also enhance the tonic GABAergic transmission in pyramidal neurons. We therefore measured the effect of AF-16 on the tonic $\mathrm{GABA}_{\mathrm{A}}$ receptor-mediated current in CA1 pyramidal neurons. By using the same analytical approach used to measure the tonic $\mathrm{GABA}_{\mathrm{A}}$ receptor-mediated tonic current in the interneurons, $\mathrm{AF}$ 16 did not significantly alter the change in holding current (AF16: $12 \pm 1.5 \mathrm{pA}, n=7$, compared to control: $15 \pm 1.6 \mathrm{pA}, n=9$, $p=0.22$, paired $t$-test) (Figure 6A) or in input resistance (AF-16: $16 \pm 5 \%, n=5$, compared to control: $15 \pm 2 \%, n=8, p=0.74$, paired $t$-test) (Figure 6B) after PTX application. In this specific set of experiments both Wistar and Sprague-Dawley rats were used.
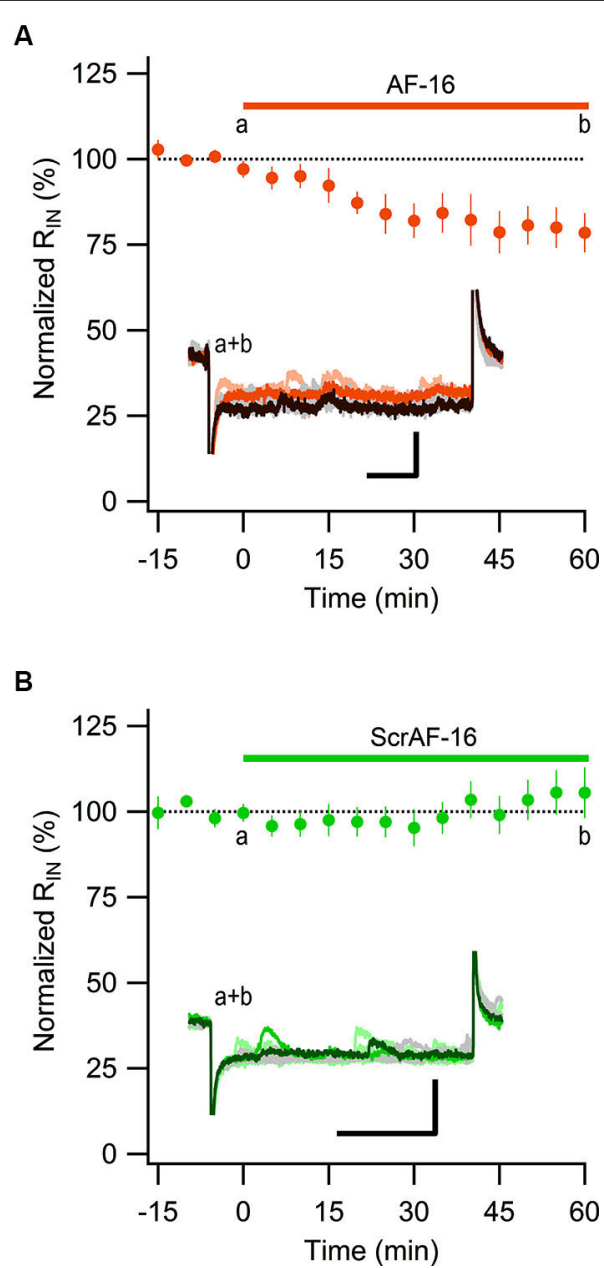

FIGURE 4 | AF-16 reduces the input resistance in CA1 stratum radiatum interneurons. (A) Summary graph of average ( \pm s.e.m.) input resistance during application of AF-16 in CA1 stratum radiatum interneurons $(n=8)$. Representative traces from time points a (orange/light orange colors) and b (dark brown/gray colors) are shown inside the graph, scale bar represents $30 \mathrm{pA}$ and $75 \mathrm{~ms}$. (B) Summary graph of average ( \pm s.e.m.) input resistance during application of scrambled AF-16 in CA1 stratum radiatum interneurons $(n=8)$. Representative traces from time points a (green/light green colors) and b (dark green/gray colors) are shown inside the graph, scale bar represents $30 \mathrm{pA}$ and $75 \mathrm{~ms}$.

The results were pooled since there was no significant difference between the two strains (changes in holding current after PTX applications were: $12.8 \pm 1.8 \mathrm{pA}, n=4$ in Wistar AF-16 treated compared to $11.2 \pm 3.1 \mathrm{pA}, n=3$ in Sprague Dawley AF-16 treated, $p=0.65$ (independent samples $t$-test) and $14.1 \pm 1.7 \mathrm{pA}$, $n=7$ in Wistar control compared to $18.4 \pm 4.3 \mathrm{pA}, n=2$ in Sprague Dawley control, $p=0.29$ (independent samples $t$-test)).

\section{DISCUSSION}

In the present study we have investigated how the endogenous peptide AF affects GABAergic transmission onto pyramidal neurons and stratum radiatum GABAergic interneurons in the hippocampus. In pyramidal neurons we found that AF causes a reduction in the frequency of action potential-dependent, but not 
A
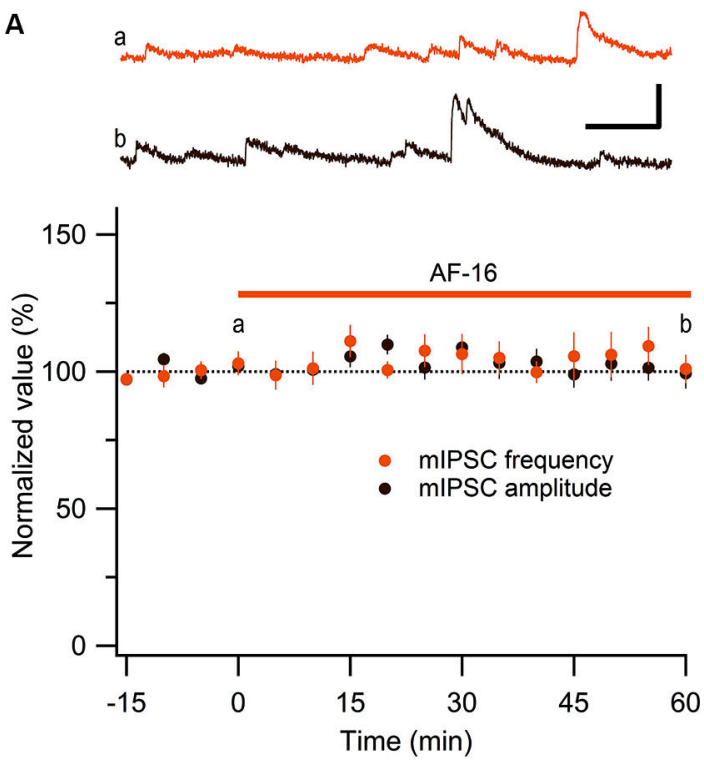

B

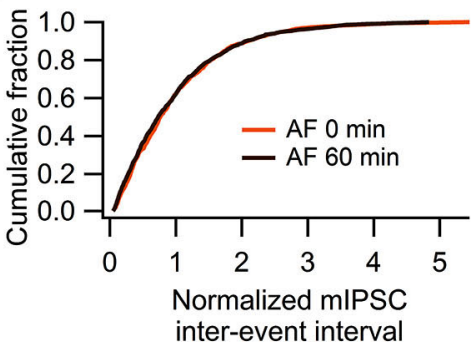

C

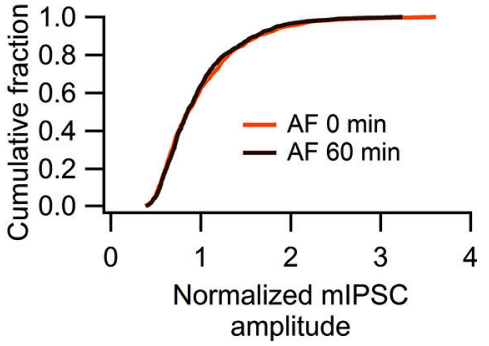

FIGURE 5 | No effect of AF-16 on mIPSCs in CA1 stratum radiatum interneurons. (A) Summary graph of average ( \pm s.e.m.) frequencies and amplitudes of recorded mIPSCs in CA1 stratum radiatum interneurons $(n=6)$ during application of AF-16. Representative traces from time points a (orange trace before the application of AF) and $b$ (dark brown trace 60 min after the application of AF) are shown at the top, scale bar represents $20 \mathrm{pA}$ and $100 \mathrm{~ms}$. (B) Effect of AF-16 on the cumulative distribution of mIPSC inter-event intervals $(n=6)$. (C) Effect of AF-16 on the cumulative distribution of mIPSC amplitudes $(n=6)$. of action potential-independent, spontaneous IPSCs, and that AF did not affect the tonic GABAergic transmission. In interneurons, on the other hand, we found that AF enhances the currents through tonically active $G_{A B A}$ receptors. Phasic $G_{A B A}$ receptor-mediated synaptic transmission onto the interneurons, as measured as mIPSCs, was not affected. We thus identify AF as positive neuromodulator of tonic GABAergic signaling specifically on GABAergic interneurons.

We propose that the increase of the tonically active $G_{A B A}$ receptor-mediated current, induced by $\mathrm{AF}$, results in a decreased excitability of the interneurons. It is however not obvious that an increased tonic GABA current results in decreased excitability since GABAergic interneurons, in contrast to pyramidal neurons, do not exhibit a developmental shift from a depolarizing to a hyperpolarizing reversal potential for $\mathrm{GABA}_{\mathrm{A}}$ receptor-mediated currents (Banke and Mcbain, 2006). More specifically, stratum radiatum interneurons have been shown to exhibit a reversal potential for tonic $\mathrm{GABA}_{\mathrm{A}}$ receptor-mediated currents $(-62 \mathrm{mV})$ that is more depolarized than the resting membrane potential $(-72 \mathrm{mV})$, but more hyperpolarized than the threshold for action potential ( $-44 \mathrm{mV}$ ) (Song et al., 2011). Song et al. (2011) further showed that a low increase of the $\mathrm{GABA}_{\mathrm{A}}$ conductance can actually increase the excitability of these interneurons (via a depolarization), whereas a larger increase of the $\mathrm{GABA}_{\mathrm{A}}$ conductance results in a decreased excitation (when the shunting currents overrides the depolarization). Our findings suggest that the AF-induced increase of the tonic $\mathrm{GABA}_{\mathrm{A}}$ receptor-mediated current results in a decreased interneuronal excitability. Importantly, application of AF resulted in a reduced, not increased, frequency of spontaneous, action-potential dependent, IPSCs in CA1 pyramidal neurons. This result is also consistent with our previously reported reduction of evoked feed-forward inhibition in CA1 pyramidal neurons (Kim et al., 2005). Moreover, the temporal development of the enhanced tonic $\mathrm{GABA}_{\mathrm{A}}$ receptor currents in the interneurons paralleled that of the decreased evoked (Kim et al., 2005), and spontaneous (Figure 1), inhibitory synaptic activity onto the CA1 pyramidal neurons.

In the present study we have not examined the mechanisms by which $\mathrm{AF}$ increases the tonic $\mathrm{GABA}_{\mathrm{A}}$ receptor-mediated current in the stratum radiatum interneurons. We envision two main, non-exclusive, possible mechanisms: an increased concentration of ambient GABA, or more functionally active extrasynaptic $\mathrm{GABA}_{\mathrm{A}}$ receptors. An increased concentration of ambient GABA, produced by, for example, inhibition of GABA transporters, seems unlikely since we did not find any enhancement of the tonic GABAergic current in CA1 pyramidal neurons. It can be noted that tonic GABAergic currents may be difficult to detect in CA1 pyramidal neurons because of prominent outward rectification (Pavlov et al., 2009). In this study we have, however, recorded GABAergic currents at $0 \mathrm{mV}$ (using a low intracellular chloride concentration), and we observed prominent tonic GABAergic currents in the CA1 pyramidal neurons, but no enhancement by AF. We did not find any significant tonic GABAergic signaling in the GABAergic interneurons under baseline conditions. This discrepancy between our finding and that reported by others (Semyanov et al., 2003; Scimemi et al., 2005; Song et al., 2013) seems to be quantitative rather than qualitative. Indeed there are other reports of non-significant tonic GABAergic signaling in 
A

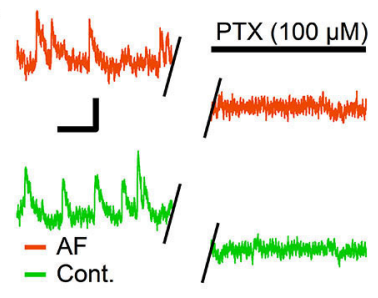

B

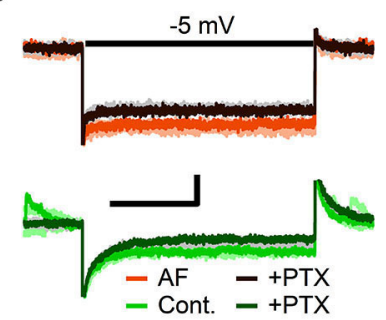

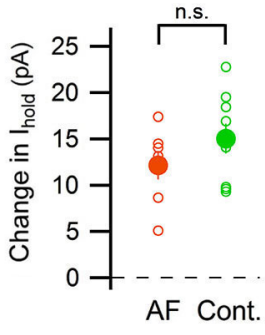

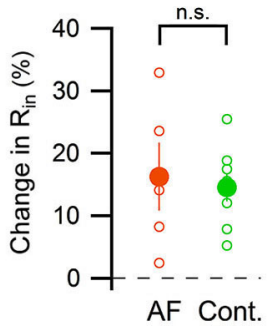

FIGURE 6 | AF-16 does not enhance tonic GABAergic transmission in CA1 pyramidal neurons. (A) Diagram showing the effect of PTX on the holding current in CA1 pyramidal neurons incubated in AF-16 $(n=7)$ and control $(n=9)$. Open circles represent the individual experiments while the filled circles represent the average ( \pm s.e.m.) values. On the left are representative traces before and after application of PTX, scale bar represents $10 \mathrm{pA}$ and $250 \mathrm{~ms}$. (B) Diagram showing the effect of PTX on the input resistance in CA1 pyramidal neurons incubated in AF-16 $(n=5)$ and control $(n=8)$. Open circles represent the individual experiments while the filled circles represent the average ( \pm s.e.m.) values. On the left are representative traces during a $-5 \mathrm{mV}$ test pulse before (orange/light orange and green/light green colors for AF and control, respectively) and after (dark brown/gray and dark green/gray colors for AF and control, respectively) application of PTX, scale bar represents $30 \mathrm{pA}$ and $75 \mathrm{~ms}$. n.s. not significant $(p>0.05)$.

interneurons in the CA1 region (Bieda and Maciver, 2004), as well as in somatostatin-positive interneurons in layer $2 / 3$ of the frontoparietal cortex (Vardya et al., 2008). It appears that this difference relates to differential basal conditions including different strains, gender and age of the animals used (Marchionni et al., 2007).

In CA1 pyramidal neurons tonic GABAergic signaling is mediated mainly via $\alpha 5$-containing $\mathrm{GABA}_{\mathrm{A}}$ receptors, whereas $\delta$ containing $\mathrm{GABA}_{\mathrm{A}}$ receptors mediate tonic GABAergic signaling in dentate granule cells and many GABAergic interneurons (Gao and Fritschy, 1994; Sperk et al., 1997; Glykys et al., 2008; Mann and Mody, 2010; Ferando and Mody, 2012). A differential modulation of tonic GABAergic signaling mediated by different types of $\mathrm{GABA}_{\mathrm{A}}$ receptors has previously been reported (Glykys et al., 2007; Jin et al., 2011; Tao et al., 2013). It is thus possible that the presently found differential effect of AF on tonic GABAergic signaling could be explained by a selective increase in the number and/or efficacy of extrasynaptic $G_{A B A_{A}}$ receptors in GABAergic interneurons that normally express $\delta$-containing $\mathrm{GABA}_{\mathrm{A}}$ receptors. Such an increase of extrasynaptic $\mathrm{GABA}_{\mathrm{A}}$ receptors could be mediated by exocytosis and membrane insertion of $\mathrm{GABA}_{\mathrm{A}}$ receptors (Saliba et al., 2012). We note, however, that the

AF-induced increase of tonic GABAergic signaling in the interneurons develops over tens of minutes, indicating that the putative exocytosis might include synthesis of new receptors. It is also important to note that the proposed AF-induced membrane insertion of new GABA receptors is exclusive for the extrasynaptic membrane since AF did not induce any increase of the mIPSC amplitude in the GABAergic interneurons, or in the CA1 pyramidal neurons. Our study thus adds to the concept of differential modulation of phasic and tonic GABAergic signaling. It also adds to the emerging concept of differential modulation of tonic GABAergic signaling in different types of neurons. Since the modulation by different neuromodulators likely differs with gender, age, species, strain, etc, the emerging concept of differential modulation may also help to explain the reported variation in tonic GABAergic signaling in different studies.

In the CA1 region the interneurons can be divided into different groups based on location, morphology, physiological and molecular features (Ascoli et al., 2008; Klausberger and Somogyi, 2008). The cell bodies of the interneurons in the CA1 region are located in stratum radiatum as well as stratum lacunosummoleculare, pyramidale and oriens. In the present study we only investigated interneurons with their cell bodies located in the stratum radiatum, with no further characterization. This selection likely includes cholecystokinin-positive Schaffer-collateral associated and apical dendrite innervating interneurons, but excludes parvalbumin-positive interneurons (Klausberger and Somogyi, 2008). We therefore do not know if our findings also apply to interneurons located in other parts of the CA1 region. However, all the interneurons investigated displayed similar effects elicited by AF. Moreover, the about $20 \%$ reduction in the frequency of sIPSCs in CA1 pyramidal neurons by AF (Figure 1) is similar to the reduction of evoked feed-forward inhibition (Kim et al., 2005), suggesting that the presently described effect of AF may be general among hippocampal interneurons.

The modulation of interneuronal extrasynaptic $\mathrm{GABA}_{\mathrm{A}}$ receptors by $\mathrm{AF}$ adds to the concept that extrasynaptic $\mathrm{GABA}_{\mathrm{A}}$ receptors are an important target for neuromodulation (Garcia et al., 2010; Jin et al., 2011; Ferando and Mody, 2012; Tao et al., 2013). $\mathrm{GABA}_{\mathrm{A}}$ receptors are however not only expressed on neurons in the central nervous system, but also in the enteric nervous system (Krantis, 2000), as well as on non-neuronal cells such as immune cells (Bjurstom et al., 2008) and endocrine pancreatic cells (Jin et al., 2013). Dysregulation of $\mathrm{GABA}_{\mathrm{A}}$ receptors on these cells has been implicated in immunological disorders (Bjurstom et al., 2008) and diabetes (Taneera et al., 2012). The cellular mechanisms behind AF's anti-inflammatory and antisecretory effects have not been established, but our present results suggest the possibility that one such cellular mechanism is mediated via a positive modulation of $\mathrm{GABA}_{\mathrm{A}}$ receptors on certain neuronal and nonneuronal cells.

\section{AUTHOR CONTRIBUTIONS}

Joakim Strandberg, Stefan Lange, Fredrik Asztely and Eric Hanse designed research; Joakim Strandberg and Catarina Lindquist performed research; Joakim Strandberg analyzed data; Joakim Strandberg, Fredrik Asztely and Eric Hanse wrote the paper. All authors read and commented on the final draft of the paper. 


\section{ACKNOWLEDGMENTS}

This work was supported by the Swedish Research Council (K2013-62X-12600-16-4), Swedish State Support for Clinical Research (ALFGBG-136991), The Swedish Brain Foundation (FO2011-003) and Swedish Government under the LUA/ALF agreement (grant \# 71570).

\section{REFERENCES}

Banke, T. G., and Mcbain, C. J. (2006). GABAergic input onto CA3 hippocampal interneurons remains shunting throughout development. J. Neurosci. 26, 1172011725. doi: 10.1523/jneurosci.2887-06.2006

Bezaire, M. J., and Soltesz, I. (2013). Quantitative assessment of CA1 local circuits: knowledge base for interneuron-pyramidal cell connectivity. Hippocampus 23, 751-785. doi: 10.1002/hipo.22141

Bieda, M. C., and Maciver, M. B. (2004). Major role for tonic GABAA conductances in anesthetic suppression of intrinsic neuronal excitability. J. Neurophysiol. 92, 1658-1667. doi: 10.1152/jn.00223.2004

Bjurstom, H., Wang, J., Ericsson, I., Bengtsson, M., Liu, Y., Kumar-Mendu, S., et al. (2008). GABA, a natural immunomodulator of T lymphocytes. J. Neuroimmunol. 205, 44-50. doi: 10.1016/j.jneuroim.2008.08.017

Davidson, T. S., and Hickey, W. F. (2004a). Antisecretory factor expression is regulated by inflammatory mediators and influences the severity of experimental autoimmune encephalomyelitis. J. Leukoc. Biol. 76, 835-844. doi: 10.1189/jlb. 0204085

Davidson, T. S., and Hickey, W. F. (2004b). Distribution and immunoregulatory properties of antisecretory factor. Lab. Invest. 84, 307-319. doi: 10. 1038/labinvest.3700036

Eriksson, A., Shafazand, M., Jennische, E., and Lange, S. (2003). Effect of antisecretory factor in ulcerative colitis on histological and laborative outcome: a short period clinical trial. Scand. J. Gastroenterol 38, 1045-1049. doi: 10. 1080/00365520310005064

Ferando, I., and Mody, I. (2012). GABAA receptor modulation by neurosteroids in models of temporal lobe epilepsies. Epilepsia 53(Suppl. 9), 89-101. doi: 10. 1111/epi.12038

Gao, B., and Fritschy, J. M. (1994). Selective allocation of GABAA receptors containing the alpha 1 subunit to neurochemically distinct subpopulations of rat hippocampal interneurons. Eur. J. Neurosci. 6, 837-853. doi: 10.1111/j.14609568.1994.tb00994.x

Garcia, P. S., Kolesky, S. E., and Jenkins, A. (2010). General anesthetic actions on GABA(A) receptors. Curr. Neuropharmacol. 8, 2-9. doi: 10. 2174/157015910790909502

Glykys, J., Mann, E. O., and Mody, I. (2008). Which GABA(A) receptor subunits are necessary for tonic inhibition in the hippocampus? J. Neurosci. 28, 1421-1426. doi: 10.1523/jneurosci.4751-07.2008

Glykys, J., and Mody, I. (2007). The main source of ambient GABA responsible for tonic inhibition in the mouse hippocampus. J. Physiol. 582, 1163-1178. doi: 10. 1113/jphysiol.2007.134460

Glykys, J., Peng, Z., Chandra, D., Homanics, G. E., Houser, C. R., and Mody, I. (2007). A new naturally occurring GABA(A) receptor subunit partnership with high sensitivity to ethanol. Nat. Neurosci. 10, 40-48. doi: 10.1038/nn1813

Graber, D. J., Harris, B. T., and Hickey, W. F. (2011). Strain-dependent variation in the early transcriptional response to CNS injury using a cortical explant system. J. Neuroinflammation 8:122. doi: 10.1186/1742-2094-8-122

Jennische, E., Bergström, T., Johansson, M., Nyström, K., Tarkowski, A., Hansson, H. A., et al. (2008). The peptide AF-16 abolishes sickness and death at experimental encephalitis by reducing increase of intracranial pressure. Brain Res. 1227, 189-197. doi: 10.1016/j.brainres.2008.05.083

Jensen, K., Chiu, C. S., Sokolova, I., Lester, H. A., and Mody, I. (2003). GABA transporter-1 (GAT1)-deficient mice: differential tonic activation of GABAA versus GABAB receptors in the hippocampus. J. Neurophysiol. 90, 2690-2701. doi: $10.1152 /$ jn. 00240.2003

Jin, Z., Jin, Y., Kumar-Mendu, S., Degerman, E., Groop, L., and Birnir, B. (2011). Insulin reduces neuronal excitability by turning on $\mathrm{GABA}(\mathrm{A})$ channels that generate tonic current. PLoS One 6:e16188. doi: 10.1371/journal.pone.0016188

Jin, Z., Mendu, S. K., and Birnir, B. (2013). GABA is an effective immunomodulatory molecule. Amino Acids 45, 87-94. doi: 10.1007/s00726-011-1193-7
Johansson, E., Al-Olama, M., Hansson, H. A., Lange, S., and Jennische, E. (2013). Diet-induced antisecretory factor prevents intracranial hypertension in a dosage-dependent manner. Br. J. Nutr. 109, 2247-2252. doi: 10. 1017/s0007114512004552

Johansson, E., Jennische, E., Lange, S., and Lönnroth, I. (1997a). Antisecretory factor suppresses intestinal inflammation and hypersecretion. Gut 41, 642-645. doi: 10.1136/gut.41.5.642

Johansson, E., Lange, S., and Lönnroth, I. (1997b). Identification of an active site in the antisecretory factor protein. Biochim. Biophys. Acta 1362, 177-182. doi: 10. 1016/s0925-4439(97)00066-5

Johansson, E., Lönnroth, I., Jonson, I., Lange, S., and Jennische, E. (2009). Development of monoclonal antibodies for detection of Antisecretory Factor activity in human plasma. J. Immunol. Methods 342, 64-70. doi: 10.1016/j.jim.2008.11. 018

Johansson, E., Lönnroth, I., Lange, S., Jonson, I., Jennische, E., and Lönnroth, C. (1995). Molecular cloning and expression of a pituitary gland protein modulating intestinal fluid secretion. J. Biol. Chem. 270, 20615-20620. doi: 10. $1074 /$ jbc. 270.35 .20615

Kim, M., Wasling, P., Xiao, M. Y., Jennische, E., Lange, S., and Hanse, E. (2005). Antisecretory factor modulates GABAergic transmission in the rat hippocampus. Regul. Pept. 129, 109-118. doi: 10.1016/j.regpep.2005.01.018

Klausberger, T. (2009). GABAergic interneurons targeting dendrites of pyramidal cells in the CA1 area of the hippocampus. Eur. J. Neurosci. 30, 947-957. doi: 10. 1111/j.1460-9568.2009.06913.x

Klausberger, T., and Somogyi, P. (2008). Neuronal diversity and temporal dynamics: the unity of hippocampal circuit operations. Science 321, 53-57. doi: 10. 1126/science.1149381

Krantis, A. (2000). GABA in the mammalian enteric nervous system. News. Physiol. Sci. 15, 284-290.

Lange, S., Jennische, E., Johansson, E., and Lönnroth, I. (1999). The antisecretory factor: synthesis and intracellular localisation in porcine tissues. Cell Tissue Res. 296, 607-617. doi: 10.1007/s004410051322

Lange, S., and Lönnroth, I. (2001). The antisecretory factor: synthesis, anatomical and cellular distribution and biological action in experimental and clinical studies. Int. Rev. Cytol. 210, 39-75. doi: 10.1016/s0074-7696(01)10003-3

Mane, J., Loren, V., Pedrosa, E., Ojanguren, I., Domenech, E., Gassull, M. A., et al. (2011). Therapeutic effect of antisecretory factor-rich egg yolk on the late phases of 2,4,6-trinitrobenzenesulphonic acid colitis in mice. Br. J. Nutr. 106, 15221528. doi: $10.1017 / \mathrm{s} 0007114511002042$

Mann, E. O., and Mody, I. (2010). Control of hippocampal gamma oscillation frequency by tonic inhibition and excitation of interneurons. Nat. Neurosci. 13, 205-212. doi: 10.1038/nn.2464

Marchionni, I., Omrani, A., and Cherubini, E. (2007). In the developing rat hippocampus a tonic GABAA-mediated conductance selectively enhances the glutamatergic drive of principal cells. J. Physiol. 581, 515-528. doi: 10.1113/jphysiol. 2006.125609

Pavlov, I., Savtchenko, L. P., Kullmann, D. M., Semyanov, A., and Walker, M. C. (2009). Outwardly rectifying tonically active GABAA receptors in pyramidal cells modulate neuronal offset, not gain. J. Neurosci. 29, 15341-15350. doi: 10. 1523/jneurosci.2747-09.2009

Petilla Interneuron Nomenclature Group, Ascoli, G. A., Alonso-Nanclares, L., Anderson, S. A., Barrionuevo, G., Benavides-Piccione, R., et al. (2008). Petilla terminology: nomenclature of features of GABAergic interneurons of the cerebral cortex. Nat. Rev. Neurosci. 9, 557-568. doi: 10.1038/nrn2402

Saliba, R. S., Kretschmannova, K., and Moss, S. J. (2012). Activity-dependent phosphorylation of GABAA receptors regulates receptor insertion and tonic current. EMBO J. 31, 2937-2951. doi: 10.1038/emboj.2012.109

Scimemi, A., Semyanov, A., Sperk, G., Kullmann, D. M., and Walker, M. C. (2005). Multiple and plastic receptors mediate tonic GABAA receptor currents in the hippocampus. J. Neurosci. 25, 10016-10024. doi: 10.1523/jneurosci.2520-05. 2005

Semyanov, A., Walker, M. C., and Kullmann, D. M. (2003). GABA uptake regulates cortical excitability via cell type-specific tonic inhibition. Nat. Neurosci. 6, 484490. doi: $10.1038 / \mathrm{nn} 1043$

Song, I., Savtchenko, L., and Semyanov, A. (2011). Tonic excitation or inhibition is set by $\operatorname{GABA}(\mathrm{A})$ conductance in hippocampal interneurons. Nat. Commun. 2: 376. doi: 10.1038/ncomms 1377

Song, I., Volynski, K., Brenner, T., Ushkaryov, Y., Walker, M., and Semyanov, A. (2013). Different transporter systems regulate extracellular GABA from 
vesicular and non-vesicular sources. Front. Cell. Neurosci. 7:23. doi: 10. 3389/fncel.2013.00023

Sperk, G., Schwarzer, C., Tsunashima, K., Fuchs, K., and Sieghart, W. (1997). GABA(A) receptor subunits in the rat hippocampus I: immunocytochemical distribution of 13 subunits. Neuroscience 80, 987-1000. doi: 10.1016/s03064522(97)00146-2

Säljö, A., Bolouri, H., Mayorga, M., Svensson, B., and Hamberger, A. (2010). Lowlevel blast raises intracranial pressure and impairs cognitive function in rats: prophylaxis with processed cereal feed. J. Neurotrauma 27, 383-389. doi: 10. 1089/neu.2009.1053

Taneera, J., Jin, Z., Jin, Y., Muhammed, S. J., Zhang, E., Lang, S., et al. (2012). Gamma-aminobutyric acid (GABA) signalling in human pancreatic islets is altered in type 2 diabetes. Diabetologia 55, 1985-1994. doi: 10.1007/s00125-0122548-7

Tao, W., Higgs, M. H., Spain, W. J., and Ransom, C. B. (2013). Postsynaptic GABAB receptors enhance extrasynaptic GABAA receptor function in dentate gyrus granule cells. J. Neurosci. 33, 3738-3743. doi: 10.1523/jneurosci.4829-12. 2013

Ulgheri, C., Paganini, B., and Rossi, F. (2010). Antisecretory factor as a potential health-promoting molecule in man and animals. Nutr. Res. Rev. 23, 300-313. doi: $10.1017 /$ s0954422410000193
Vardya, I., Drasbek, K. R., Dosa, Z., and Jensen, K. (2008). Cell type-specific GABA(A) receptor-mediated tonic inhibition in mouse neocortex. J. Neurophysiol. 100, 526-532. doi: 10.1152/jn.01224.2007

Conflict of Interest Statement: The authors declare that the research was conducted in the absence of any commercial or financial relationships that could be construed as a potential conflict of interest.

Received: 27 September 2013; accepted: 08 January 2014; published online: 28 January 2014.

Citation: Strandberg J, Lindquist C, Lange S, Asztely F and Hanse E (2014) The endogenous peptide antisecretory factor promotes tonic GABAergic signaling in CA1 stratum radiatum interneurons. Front. Cell. Neurosci. 8:13. doi: $10.3389 /$ fncel.2014.00013

This article was submitted to the journal Frontiers in Cellular Neuroscience.

Copyright () 2014 Strandberg, Lindquist, Lange, Asztely and Hanse. This is an openaccess article distributed under the terms of the Creative Commons Attribution License (CC BY). The use, distribution or reproduction in other forums is permitted, provided the original author(s) or licensor are credited and that the original publication in this journal is cited, in accordance with accepted academic practice. No use, distribution or reproduction is permitted which does not comply with these terms. 